La Revue

des Droits

de l'Homme

\section{La Revue des droits de l'homme}

Revue du Centre de recherches et d'études sur les droits fondamentaux

Actualités Droits-Libertés | 2011

COMITE EUROPEEN DES DROITS SOCIAUX

Mesures françaises à l'égard des Roms

COMITE EUROPEEN DES DROITS SOCIAUX

\title{
Diane Roman
}

\section{OpenEdition}

Journals

Édition électronique

URL : http://journals.openedition.org/revdh/3731

DOI : 10.4000/revdh.3731

ISSN : 2264-119X

Éditeur

Centre de recherches et d'études sur les droits fondamentaux

Référence électronique

Diane Roman, "Mesures françaises à l'égard des Roms », La Revue des droits de l'homme [En ligne], Actualités Droits-Libertés, mis en ligne le 02 février 2011, consulté le 19 avril 2019. URL : http:// journals.openedition.org/revdh/3731 ; DOI : 10.4000/revdh.3731

Ce document a été généré automatiquement le 19 avril 2019

Tous droits réservés 


\title{
COMITE EUROPEEN DES DROITS SOCIAUX
}

\section{Mesures françaises à l'égard des Roms}

\author{
COMITE EUROPEEN DES DROITS SOCIAUX
}

Diane Roman

1 La première décision que le président Jimena Quesada a signée dans ses nouvelles fonctions de Président du Comité européen des droits sociaux intéressera tout particulièrement la France. Il s'agit de la déclaration de recevabilité d'une réclamation collective présentée par le Centre sur les droits au logement et les expulsions (COHRE) contre la France (Réclamation n 63/2010 - déclarée recevable le 25 janvier 2011 mais non encore publiée sur le site du Comité). La réclamation concerne les expulsions des Roms de leurs logements et de la France pendant l'été 2010. Le COHRE allègue que ces expulsions violent l'article 16 (droit de la famille à une protection sociale, juridique et économique), l'article 31 (droit au logement) et l'article $19 \$ 8$ (garanties relatives à l'expulsion) de la Charte sociale révisée. L'organisation réclamante allègue également que les faits en question constituent une discrimination (article E) dans la jouissance de ces droits mentionnés.

2 Est ici visée, dans cette nouvelle réclamation, l'aggravation de la politique française à l'été 2010 à l'égard des Roms (pour une analyse juridique complète, v. Serge Slama, Evacuation et expulsion des Roms roumains et bulgares : l'absurde stratégie de la carotte et du bâton). Comme le souligne l'association réclamante, la situation des Roms s'est considérablement détériorée en France après que le Président Sarkozy eut annoncé, les 21 et 28 juillet 2010, la mise en œuvre d'une nouvelle politique concertée d'évacuation forcée et d'expulsion en masse de campements dits illégaux. Dans le mois qui a suivi ces annonces, 950 Roms ont dû repartir vers la Roumanie et la Bulgarie, soit au total plus de 5000 personnes pour 2010. Ces expulsions ont été effectuées dans un fort climat de contrainte et de violence. Ainsi, certaines ont eu lieu à l'aube et des familles ont été séparées de force. De plus, aucune solution de relogement ne leur a été proposée. L'association pointe du doigt non seulement les effets discriminatoires sur la population rom de telles mesures, mais plus encore une "évidente volonté de discrimination », reflétée 
par les termes de la - désormais célèbre quoique rapidement abrogée - circulaire du 5 août 2010 diffusée aux chefs de la police en août 2010 et signée du Directeur de cabinet du Ministre de l'Intérieur indiquait que: « trois cent campements ou installations illicites devr [aient] avoir été évacués d'ici trois mois, en priorité ceux des Roms ", et qu'«il rev[enait] donc, dans chaque département, aux préfets [représentants de l'Etat] d'engager une démarche systématique de démantèlement des camps illicites, en priorité ceux de Roms. ».

La décision de recevabilité ne préjuge pas du bien-fondé de la réclamation. Elle s'inscrit dans un contexte politique et juridique néanmoins tout à fait particulier et un suivi attentif s'imposera. La politique française à l'égard des Roms a en effet été déclarée contraire aux exigences de la Charte sociale dans un passé très proche (V. Comité européen des droits sociaux, Décision sur le bien-fondé, 19 octobre 2009, Centre européen des droits des Roms (CEDR) c. France, Réclamation n51/2008, - ADL du 2 mars 2010 et ADL du 14 octobre 2010 ; v. une compilation des décisions sur le bien-fondé relatives au Roms et aux Gens du Voyage ainsi que la fiche d'information sur les droits des Roms ; et notamment ADL du 30 janvier 2010) et le tournant sécuritaire de l'été 2010 a suscité une condamnation unanime des organisations internationales et européennes.

Comité européen des droits sociaux, Déclaration de recevabilité, 25 janvier 2011, Centre sur les droits au logement et les expulsions (COHRE) contre la France, Réclamation $n^{\circ}$ 63/2010 - Déclaration non encore publiée sur le site du Comité

\section{AUTEUR}

\section{DIANE ROMAN}

Diane Roman est professeure de droit public à l'Université François-Rabelais de Tours. 